\title{
POLIMERIZAÇÃO 1,4-CIS DE BUTADIENO COM SISTEMAS CATALÍTICOS ZIEGLER-NATTA À BASE DE NEODÍMIO
}

Ivana L. Mello, Fernanda M. B. Coutinho* e Bluma G. Soares

Instituto de Macromoléculas Prof. Eloisa Mano, Universidade Federal do Rio de Janeiro, Cidade Universitária da Ilha do Fundão, Bloco J, CP 68525, 21945-970 Rio de Janeiro - RJ

Denise S. S. Nunes, Marcos A. S. Costa e Luiz Claudio de Santa Maria

Instituto de Química, Universidade do Estado do Rio de Janeiro, Rua São Francisco Xavier, 524, Pavilhão Haroldo Lisboa da Cunha, $4^{\circ}$ andar, 20559-900 Rio de Janeiro - RJ

Recebido em 15/4/03; aceito em 21/7/03

\begin{abstract}
cis-1,4 POLYMERIZATION OF BUTADIENE WITH ZIEGLER-NATTA CATALYST SYSTEMS BASED ON NEODYMIUM. Nowadays the catalyst systems based on neodymium are the ones most used in the high cis polybutadiene production. These systems contain a neodymium compound (catalyst), an alkylaluminium compound (cocatalyst) and a halogen compound (halogenating agent). The microstructure, molecular weight characteristics and the reaction activity are influenced by the nature and concentration of catalyst system components. Those characteristics are also affected by the polymerization conditions. This paper presents a brief review on 1,4-cis-butadiene polymerization on neodymium catalysts.
\end{abstract}

Keywords: high cis polybutadiene; Ziegler-Natta catalyst; neodymium catalysts.

\section{INTRODUÇÃO}

O polibutadieno alto cis (BR alto cis) é um dos principais elastômeros utilizados na produção do chamado pneu ecológico. Essa denominação deve-se ao fato de esse tipo de pneu apresentar menor resistência ao rolamento e assim liberar menor quantidade de calor, o que garante maior economia de combustível (cerca de 5\%) e, conseqüentemente, um menor volume de substâncias tóxicas é liberado na atmosfera. Para selecionar a melhor rota de produção do polibutadieno alto cis, é necessário avaliar as diferentes tecnologias comercialmente disponíveis. A tecnologia que utiliza os catalisadores à base de lantanídeos (neodímio, por exemplo) é a mais recente, e foi a mais empregada na última década. Os sistemas à base de neodímio operam adiabaticamente, com solventes alifáticos, além de alcançarem elevadas conversões com alto teor de sólidos e baixo tempo de residência nos reatores, o que resulta em alta produtividade. A conversão quase total do monômero, bem superior à das demais tecnologias (níquel, cobalto e titânio), permite a eliminação da etapa de recuperação de monômero, muitas vezes dispendiosa e comple$\mathrm{xa}$, reduzindo os investimentos e custos operacionais. Assim, considerando os aspectos abordados, a tecnologia de neodímio representa economia de energia e investimento, além de apresentar alta produtividade $^{1-7}$

Os sistemas catalíticos à base de lantanídeos podem ser divididos em três grupos distintos, de acordo com sua composição e estereoespecificidade ${ }^{8-11}$.

Nos catalisadores do Grupo I, o composto de lantanídeo (Ln) é representado por seu haleto ou um complexo do haleto $\left(\mathrm{LnHal}_{3} 3 \mathrm{~L}\right.$, onde L é um ligante orgânico doador de elétrons). Os ligantes mais usados são os ésteres do ácido $o$-fosfórico, sulfóxidos, álcoois e éteres cíclicos. Esses compostos, juntamente com um alquilalumínio, dão origem a sistemas catalíticos capazes de produzir polibutadieno com alto teor de unidades 1,4-cis.

\footnotetext{
*e-mail: fern@ima.ufrj.br
}

O Grupo II inclui catalisadores em que o componente inicial de lantanídeo não contém halogênio. Os catalisadores desse tipo abrangem carboxilatos, $\mathrm{Ln}(\mathrm{RCOO})_{3}$, alquilfosfatos, $\mathrm{Ln}\left(\mathrm{R}_{2} \mathrm{PO}_{4}\right)_{3} \mathrm{ou}$ alcoolatos de lantanídeo, $\mathrm{Ln}(\mathrm{OR})_{3}$. Os carboxilatos, que possuem boa solubilidade em hidrocarbonetos, tais como naftenatos, octanoatos e estearatos, são os mais usados. Além do composto de lantanídeo, esses sistemas devem incluir compostos contendo halogênio, tais como haletos de alquila, haletos de alquilalumínio, haletos de alquiltitânio ou halogênios em sua forma elementar. Esses constituintes têm o papel de halogenar o lantanídeo por meio de reação de troca. Os sistemas catalíticos desse grupo apresentam a mesma estereoespecificidade dos sistemas baseados em haletos de lantanídeos.

Nos catalisadores do Grupo III o composto inicial de lantanídeo contém halogênio e há formação da ligação Ln-C, como por exemplo, o sistema catalítico R'LnHal . $n$ THF/AlR , onde R' é um radical alquila e Hal é o halogênio.

A variação dos componentes do sistema catalítico pode exercer influência sobre a atividade catalítica, a microestrutura, o peso molecular e a distribuição de peso molecular do polibutadieno.

\section{Natureza química do lantanídeo}

A estereorregularidade obtida com diferentes lantanídeos é praticamente a mesma (Tabela 1) e reflete a similaridade na natureza química dos elétrons do orbital $4 \mathrm{f}$ em todos os elementos pertencentes à série lantanídica. Os orbitais 4f dos lantanídeos são fracamente envolvidos na formação das ligações químicas; e assim, a estrutura eletrônica dos centros ativos e de seus complexos com os dienos não varia com a natureza do lantanídeo. Além disso, a ligação $\pi$-alílica da unidade terminal da cadeia polimérica de um polidieno com o lantanídeo é ainda energeticamente vantajosa. Entretanto, a atividade dos catalisadores à base de lantanídeos na polimerização de dienos varia de um elemento para o outro na série. Nos catalisadores ativos, os lantanídeos permanecem no estado trivalente, conforme evidenciado por análises químicas e estudos espectrofotométricos ${ }^{12}$. Por 
outro lado, elementos que têm atividade de polimerização muito baixa ou nenhuma, tais como $\mathrm{Sm}$ e Eu, sofrem redução ao estado de oxidação +2 (inativo) $)^{12-14}$.

Duas explicações têm sido sugeridas para as diferentes atividades dos elementos quando no estado trivalente. Uma considera que a diferença de atividade é o resultado da diferença de energia durante a formação da ligação entre o dieno e os íons do lantanídeo; a outra sugere que essa diferença de atividade se deve à diferença no comprimento da ligação Ln-C nos vários elementos, que afeta a energia necessária para a inserção do monômero ${ }^{13}$.

Se a coordenação do dieno fôr o estágio limitante da velocidade de reação, durante o qual ocorre o rearranjo $\pi-\sigma$ dos centros ativos, o valor da constante de velocidade poderia estar correlacionado com a diferença entre as energias totais das estruturas $\pi$ - e $\sigma$ - dos sítios ativos $\left(\Delta \mathrm{E}=\mathrm{E}_{\pi}-\mathrm{E}_{\sigma}\right)$. Entretanto, se for a inserção do monômero o estágio limitante da velocidade, seria natural sugerir uma correlação entre a constante de velocidade e o comprimento da ligação- $\sigma$ no centro ativo ( $\left.\operatorname{Ln}-\mathrm{C}_{\alpha}\right)$, na qual ocorre predominantemente a inserção ${ }^{14}$.

Tabela 1. Microestrutura de polibutadienos preparados com catalisadores à base de diferentes lantanídeos ${ }^{11}$

\begin{tabular}{lccc}
\hline Lantanídeo & \multicolumn{3}{c}{ Polibutadieno } \\
\cline { 2 - 4 } & $1,4-$ cis & 1,4-trans & 1,2-vinila \\
\hline $\mathrm{La}$ & 97,2 & 2,1 & 0,7 \\
$\mathrm{Ce}$ & 97,2 & 2,1 & 0,7 \\
$\mathrm{Pr}$ & 97,2 & 2,2 & 0,6 \\
$\mathrm{Nd}$ & 97,3 & 2,2 & 0,5 \\
$\mathrm{Sm}$ & 98,0 & 1,6 & 0,4 \\
$\mathrm{Gd}$ & 97,3 & 2,2 & 0,5 \\
$\mathrm{~Tb}$ & 97,9 & 1,6 & 0,5 \\
$\mathrm{Dy}$ & 97,5 & 1,9 & 0,6 \\
$\mathrm{Er}$ & 93,0 & 6,1 & 0,9 \\
$\mathrm{Tm}$ & 90,6 & 8,7 & 0,7 \\
$\mathrm{Yb}$ & 97,1 & 2,6 & 0,3 \\
\hline
\end{tabular}

Em relação à velocidade de polimerização de dienos, os lantanídeos formam a seguinte série:

$\mathrm{La}<\mathrm{Ce}<\mathrm{Pr}<\mathrm{Nd}>\mathrm{Gd}>\mathrm{Tb}>\mathrm{Dy}>\mathrm{Ho}>\mathrm{Er}$

Na reação de polimerização de butadieno, a constante de velocidade de propagação, $\mathrm{k}_{\mathrm{p}}$, para os lantanídeos do subgrupo do Ce aumenta com o número atômico; para o subgrupo do $\mathrm{Yb}$, no entanto, $\mathrm{k}_{\mathrm{p}}$ diminui à medida que o número atômico aumenta (Tabela 2$)^{9,15}$.

Tabela 2. Variação da constante de velocidade de propagação $\left(\mathrm{k}_{\mathrm{p}}\right)$ em relação ao lantanídeo utilizado no catalisador ${ }^{9}$

\begin{tabular}{lccc}
\hline Lantanídeo & $\mathrm{k}_{\mathrm{p}}, \mathrm{L} / \mathrm{mol} \min$ & $C_{\mathrm{ac}} *(\%)$ & $1,4-$ cis $(\%)$ \\
\hline $\mathrm{La}$ & 10 & 12 & 95 \\
$\mathrm{Ce}$ & 40 & 9 & 95 \\
$\mathrm{Nd}$ & 140 & 7 & 95 \\
$\mathrm{Gd}$ & 130 & 5 & 95
\end{tabular}

$* C_{\mathrm{ac}}$ - Concentração de centros ativos, expressa em relação à concentração do lantanídeo

\section{Natureza química do halogênio}

O efeito da natureza química do halogênio sobre a reatividade dos centros ativos tem sido estudado para catalisadores à base de lantanídeos $9,16,17$

Jenkins e colaboradore ${ }^{16}$ estudaram o efeito da razão molar Nd:halogênio e do tipo de halogênio sobre a conversão e a distribuição de peso molecular do polibutadieno obtido com o sistema catalítico $[\mathrm{Nd}$ (carboxilato)//hidreto de diisobutilalumínio/haleto de $t$-butila]. Os autores notaram que os catalisadores baseados em cloreto de $t$-butila eram solúveis, enquanto que aqueles baseados em brometo de $t$-butila formavam um precipitado após $20 \mathrm{~h}$ de envelhecimento e os baseados em iodeto de $t$-butila precipitavam quase que imediatamente após sua síntese. A tendência para a formação de precipitado, ou seja, à heterogeneidade ou instabilidade do sistema catalítico, segue a ordem de decréscimo da eletronegatividade do halogênio envolvido, isto é, a atividade catalítica aumenta com o aumento da eletronegatividade:

\section{$\mathrm{Cl}$ (homogêneo) $>\mathrm{Br}>\mathrm{I}$ (heterogêneo)}

A influência do tipo de halogênio sobre a conversão é mostrada na Figura 1(a e b). Em relação aos catalisadores que contêm cloro, pode-se notar que a conversão é praticamente a mesma que quando se utiliza bromo. Entretanto, ocorre uma redução drástica na conversão quando se usa iodo. Isso pode ser atribuído ao fato que, com um catalisador altamente heterogêneo, é formado rapidamente, sobre a superfície da partícula de catalisador, polímero com alto peso molecular impossibilitando o acesso de novas moléculas de monômero aos sítios catalíticos, e assim é obtida baixa conversão. A atividade catalítica aumenta com o aumento da eletronegatividade do halogênio, isto é, $\mathrm{Cl}>\mathrm{Br}>>\mathrm{I}^{16}$.

Segundo Marina e colaboradores ${ }^{8}$, a atividade de sistemas catalíticos pertencentes ao Grupo II em função da natureza do halogênio segue a ordem $\mathrm{Cl}>\mathrm{Br}>\mathrm{I}>\mathrm{F}$. Sistemas contendo flúor são capazes de polimerizar dienos quando a razão molar F:Nd é superior a 10 , sendo a atividade máxima atingida quando esta razão é aproximadamente 40 (Figura 2). Esse comportamento está correlacionado com o fato de os fluoretos de dialquilalumínio, em solução, estarem associados como tetrâmeros e, por isso, a fluoração requer maiores teores desse componente.
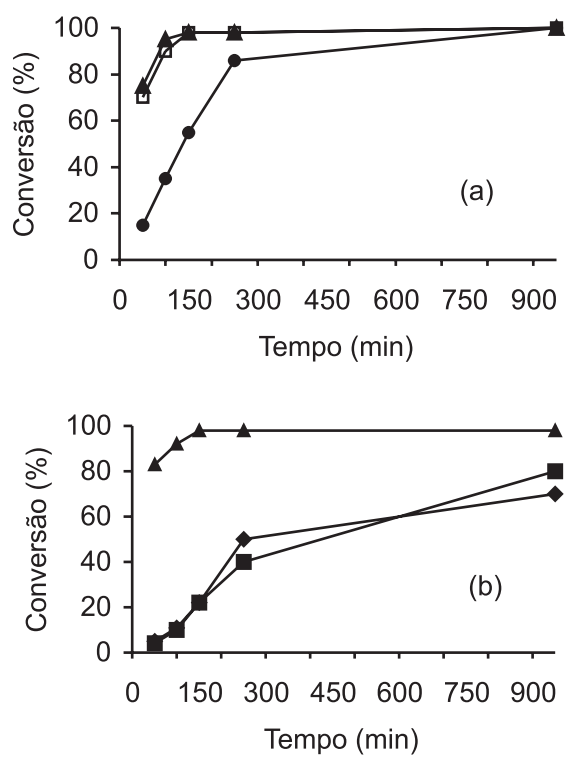

Figura 1. Influência do tipo de halogênio sobre a conversão da polimerização de butadieno: (a) - $\mathbf{\Delta}-\mathrm{Cl}: N d=3: 1,-\square-B r: N d=3: 1$, - - $B r: N d=1: 1$; (b) - $\mathbf{\Delta}$ - $C l: N d=3: 1,-$ - $I: N d=3: 1$, - $\mathbf{\square}-I: N d=1: 1$ 


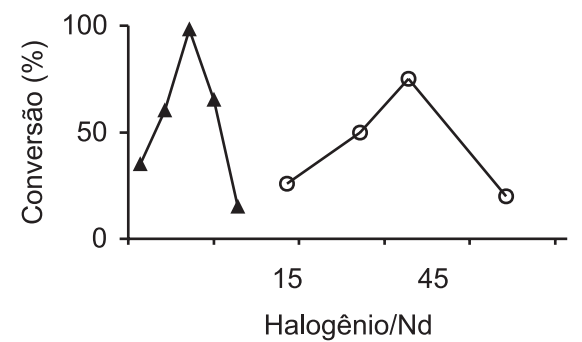

Figura 2. Conversão da polimerização de butadieno em função do halogênio utilizado: (-А-) cloro, (-O-) flúor

Wilson $^{18}$, ao estudar o efeito do componente halogenado do sistema catalítico à base de Nd sobre a distribuição de peso molecular, constatou que o polímero produzido pelo sistema que continha cloro apresentava uma distribuição mais estreita de peso molecular, do que o polibutadieno produzido com os sistemas catalíticos que continham iodo ou bromo. Segundo Wilson, isso ocorreu porque o aumento da labilidade da ligação carbono-halogênio do bromo e do iodo, em relação ao cloro, aumenta a instabilidade do catalisador resultante.

$\mathrm{O}$ efeito da variação da razão molar $\mathrm{Cl}$ :Nd para o sistema catalítico à base de versatato de neodímio $\left[\mathrm{Nd}(\mathrm{Ve})_{3}\right]$ é mostrado nas Figuras 3 e 4. Uma menor razão molar gera uma conversão mais baixa do butadieno em polímero, uma vez que um menor número de sítios catalíticos serão formados quando uma menor proporção de cloro é usada.

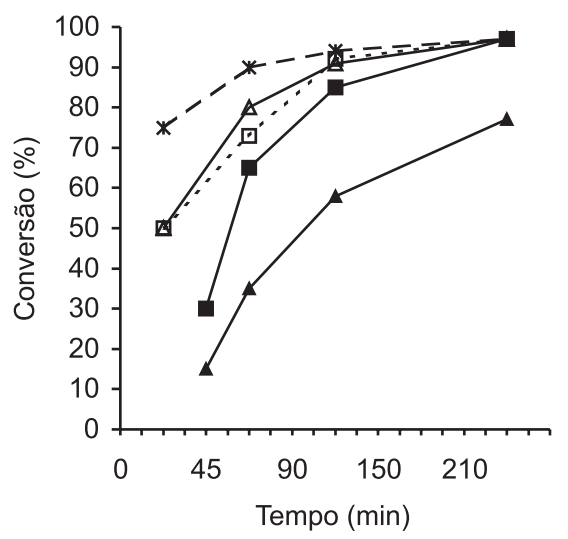

Figura 3. Influência da razão molar Cl:Nd sobre a conversão da polimerização de butadieno para o sistema catalítico $\mathrm{Nd}(\mathrm{Ve})_{3}$ /DIBAH/cloreto de t-butila: - $\mathbf{\Delta}$ - Cl:Nd=1:1, - $\mathbf{-}$ - Cl:Nd=1,5:1, - $\square-C l: N d=2: 1$, $-\triangle-C l: N d=2,5: 1,-*-C l: N d=3: 1$

Em geral, os valores da distribuição de peso molecular seguem a mesma tendência da variação da razão $\mathrm{Cl}$ :Nd. Em baixas razões $(1: 1)$ a distribuição de peso molecular é larga, devido ao menor número de sítios ativos solúveis em relação aos sítios insolúveis, produzindo polímero com alto peso molecular. Uma larga distribuição de peso molecular pode ser resultante da super-cloração dos sítios catalíticos, quando altas razões Cl:Nd (3:1) são usadas. Apesar da correlação entre a razão $\mathrm{Cl}$ :Nd e MWD não ser linear, razões molares entre $2 \mathrm{e}$ 2,5 tendem a dar um produto com distribuição de peso molecular mais estreita ${ }^{16,19,20}$.

Jenkins e Wilson ${ }^{16}$ também estudaram o efeito da razão molar halogênio: $\mathrm{Nd}$ e do tipo de halogênio sobre a microestrutura do polímero. Esses autores concluíram que esses parâmetros não alteram o teor de unidades $1,4-$ cis do polibutadieno produzido.

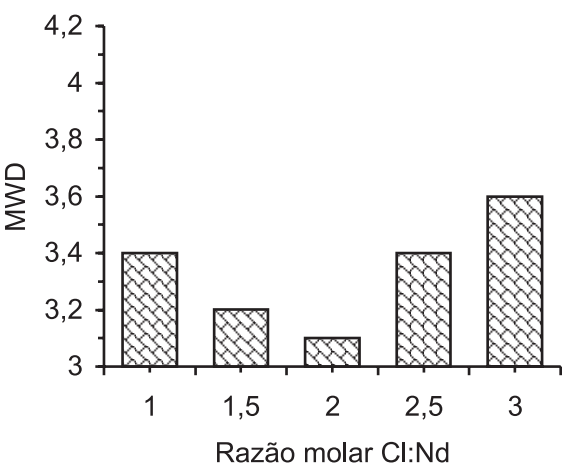

Figura 4. Influência da razão molar Cl:Nd sobre a distribuição de peso molecular (MWD) de polibutadieno

\section{Estrutura do carboxilato}

Os sistemas catalíticos à base de lantanídeos são, geralmente, baseados em sais de neodímio derivados dos ácidos naftênico, versático (neodecanóico) ou 2-etil-hexanóico (octanóico).

Os sais de neodímio derivados de ácidos monocarboxílicos lineares não apresentam uma boa solubilização em solventes alifáticos, que são os utilizados nos processos de polimerização com os sistemas catalíticos à base de neodímio. A literatura ${ }^{21}$ mostra que a solubilização em hexano ocorre, se a cadeia principal do ácido tiver cinco ou mais átomos de carbono e se tiver como ramificações grupos metila. Sendo assim, a solubilidade desses sais de neodímio em hexano segue a ordem, neoácidos > isoácidos > ácidos lineares.

Os catalisadores baseados em neoácidos são mais ativos em comparação aos isoácidos (Figura 5). Os ácidos neocarboxílicos são aqueles baseados na estrutura do ácido trialquilacético (carbono-alfa ramificado), enquanto que os isoácidos têm uma estrutura ramificada em que o isômero predominante não é ramificado no carbono alfa. A mais alta solubilidade, em hidrocarbonetos alifáticos, dos sais derivados de neoácidos resulta em uma alquilação mais rápida e mais completa, produzindo espécies catalíticas mais ativas.

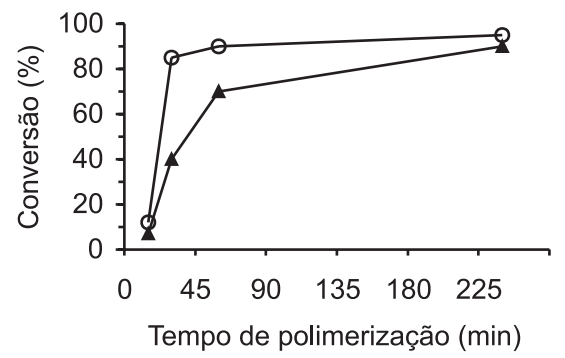

Figura 5. Atividade de catalisadores derivados de isoácido e neoácido na polimerização de butadieno: - $\mathbf{A}$ - ácido isodecanóico, - $\bigcirc$ - ácido neodecanóico

A Figura 6 mostra a variação da atividade catalítica em função do isoácido usado. Há uma indicação de que a atividade catalítica aumenta com o aumento do comprimento da cadeia do ácido. Para explicar tal fato, pode-se levar em consideração a natureza da ligação Nd-O do sal de neodímio. O aumento do comprimento da cadeia do ácido carboxílico leva a ácidos mais fracos, tornando o caráter da ligação Nd-O mais covalente. Isso facilita a alquilação do sal de $\mathrm{Nd}$ pelo alquilalumínio (primeira etapa na formação dos sítios ativos). Por outro lado, se a natureza do sal de Nd em hexano for considerada (solvatação) o efeito estérico e a entropia também devem ser levados em conta. Apesar de os sais derivados de isoácidos apresentarem 
solubilidades em hexano muito próximas, a menor solubilidade do sal derivado de ácidos com cadeias mais curtas deve prejudicar a etapa de alquilação e assim reduzir a atividade do catalisador ${ }^{21,22}$

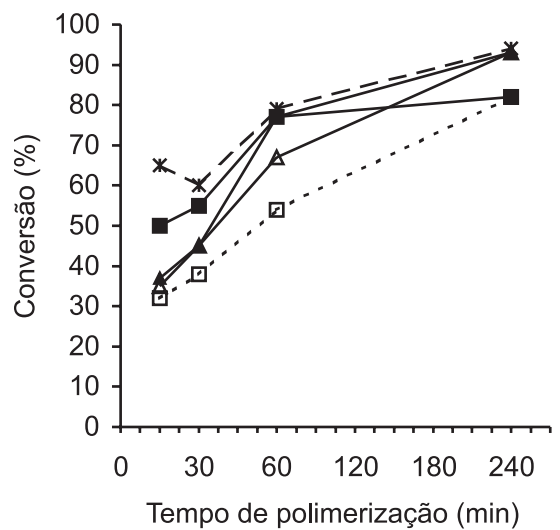

Figura 6. Efeito do comprimento da cadeia do isoácido sobre a conversão da polimerização de butadieno: - $\square$ - Ácido iso-heptanóico, - $\triangle$ - Ácido isooctanóico, - - Ácido isononanóico, - $\mathbf{\Delta - A ́ c i d o ~ i s o d e c a n o ́ i c o , ~ - * - A ́ c i d o ~}$ isotridecanóico

As atividades de catalisadores baseados em neoácidos são mostradas na Figura 7. Assim como os catalisadores baseados em isoácidos, a atividade dos sistemas à base de neoácidos parece depender do comprimento da cadeia do ácido carboxílico original, porém isso não é muito claro. Como se pode notar na Figura 7 , catalisadores derivados do ácido neo-heptanóico apresentam atividade mais baixa. Parece existir um valor de comprimento de cadeia ótimo, contendo cerca de 10 átomos de carbono, acima do qual a atividade catalítica decresce.

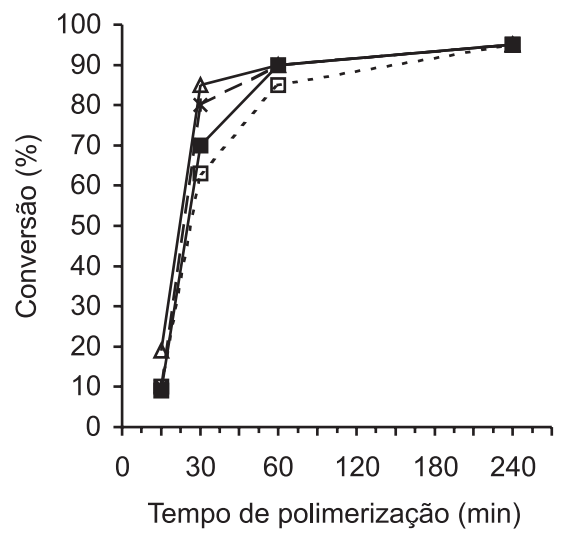

Figura 7. Efeito do comprimento da cadeia do neoácido sobre a conversão da polimerização de butadieno: - $\square$ - Ácido neo-heptanóico, $-\triangle$ - Ácido neononanóico, -*-Ácido neodecanóico, - $\mathbf{\square - A ́ c i d o ~ n e o t r i d e c a n o ́ i c o ~}$

\section{Estrutura do alquilalumínio}

A polimerização de dienos ocorre quando o sistema catalítico à base de lantanídeo contém um alquilalumínio (cocatalisador) ${ }^{23}$. Existem na literatura ${ }^{8,9,12,24-31}$ estudos sobre a influência do tipo e da concentração do alquilalumínio sobre a polimerização de butadieno.

Oehme e colaboradores ${ }^{24}$ estudaram o efeito da variação da razão molar trietilalumínio/neodímio (TEA/Nd) sobre a conversão da polimerização de butadieno e sobre o teor de unidades 1,4-cis e o peso molecular do polibutadieno produzido. Constataram que o aumento dessa razão causa um aumento na conversão (Figura 8), en- quanto que o teor de unidades 1,4-cis e o peso molecular diminuem com o aumento da razão molar TEA/Nd (Figura 9).

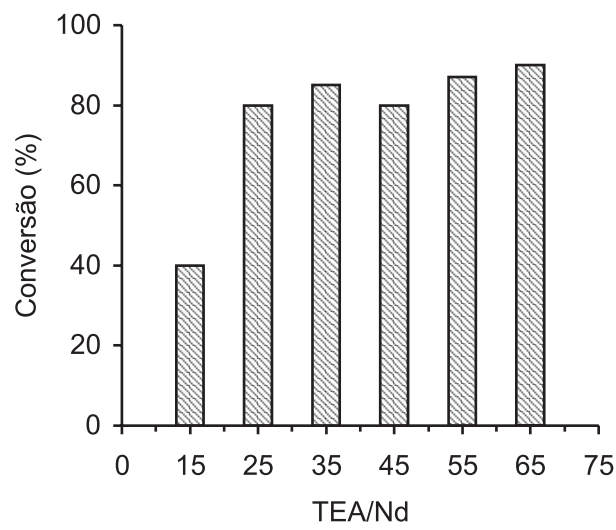

Figura 8. Influência da razão molar TEA/Nd sobre a conversão da polimerização de butadieno

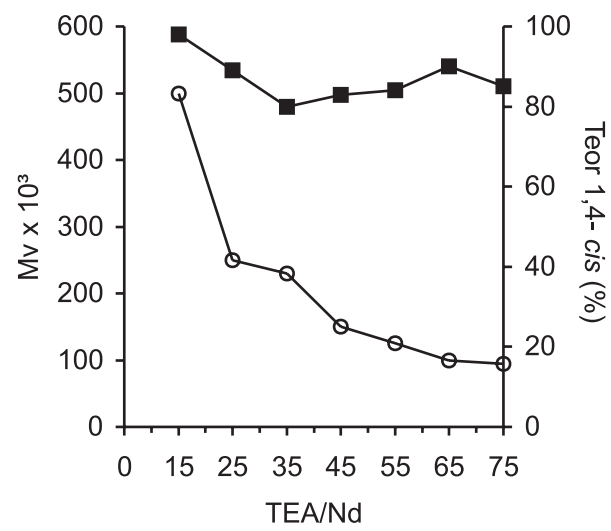

Figura 9. Influência da razão molar TEA/Nd sobre o teor de unidades 1,4-cis e sobre o peso molecular viscosimétrico $(\mathrm{Mv})$ do polibutadieno:

- - Unidades 1,4-cis; - O- Mv

Nickaf e colaboradores ${ }^{26}$ estudaram o efeito da variação da razão molar Al/Nd sobre a velocidade de polimerização e o peso molecular do polímero produzido, utilizando o triisobutilalumínio (TIBA) como agente alquilante. Os autores verificaram que o aumento da razão molar TIBA/Nd causa um aumento na velocidade de polimerização (Figura 10) e uma diminuição no peso molecular do polímero (Figura 11). Segundo os autores, a velocidade de polimerização aumentou devido ao aumento da concentração de espécies alquiladas e, portanto, ao aumento na concentração de centros ativos. Já a diminuição do peso molecular foi acompanhada por um aumento na polidispersão, o que indica que tenha havido um aumento na ocorrência de reações de transferência de cadeia com o aumento do teor de alquilalumínio.

Quirk e colaboradores ${ }^{28}$ estudaram a influência da razão molar $\mathrm{Al} / \mathrm{Nd}$ sobre a conversão da polimerização de butadieno e sobre o peso molecular, a polidispersão e a microestrutura dos polibutadienos, utilizando como cocatalisador o hidreto de diisobutilalumínio (DIBAH) (Tabela 3). Um aumento no teor de DIBAH causou, inicialmente, um aumento na conversão, porém quando a razão DIBAH/ Nd era igual ou superior a 40, a conversão permanecia igual a $98 \%$. $\mathrm{O}$ aumento na conversão, segundo os autores, pode ser devido ao aumento na concentração de espécies alquiladas e, portanto, ao aumento na concentração de espécies ativas.

A estereoespecificidade foi influenciada pela concentração de 


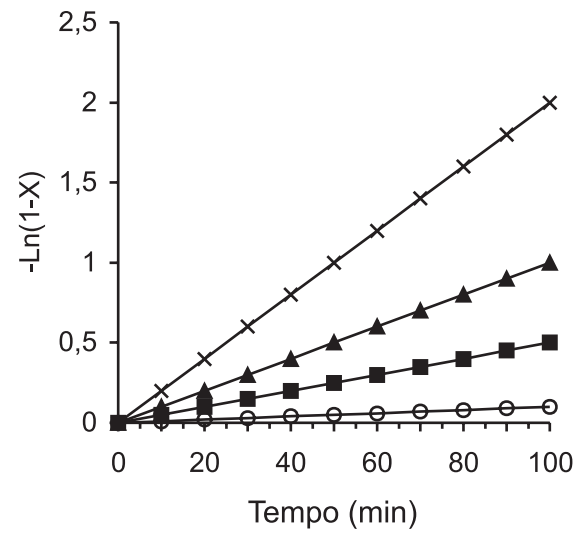

Figura 10. Influência da razão molar TIBA/Nd sobre a velocidade de polimerização: $-\mathrm{O}-\mathrm{TIBA} / \mathrm{Nd}=7,5$; $-\mathbf{\square}-\mathrm{TIBA} / \mathrm{Nd}=15 ;-\mathbf{\Delta}-\mathrm{TIBA} / \mathrm{Nd}=30$; $-\times-T I B A / N d=60$

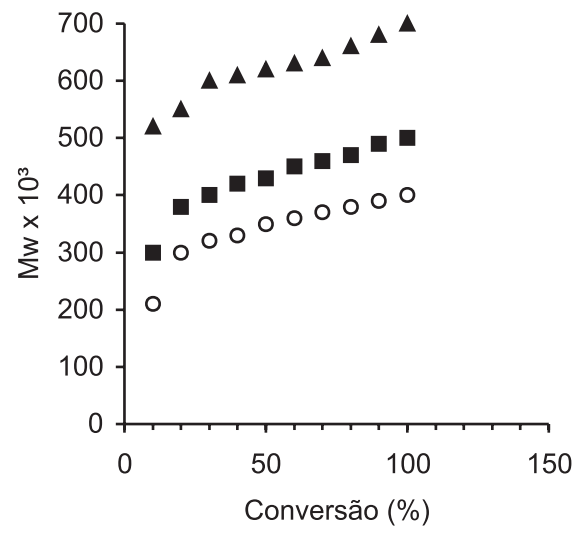

Figura 11. Influência da razão molar TIBA/Nd sobre o peso molecular do polibutadieno: $-\mathbf{\Delta}-\mathrm{TIBA} / \mathrm{Nd}=15 ;-\boldsymbol{\square}-\mathrm{TIBA} / \mathrm{Nd}=30 ;-\mathrm{O}-\mathrm{TIBA} / \mathrm{Nd}=60$

DIBAH. Quando a razão molar DIBAH/Nd foi de 60/1, o teor de isômeros 1,4-cis caiu para 96\%, enquanto que em baixas razões o teor ficou entre 98 e $99 \%$.

Como mostrado na Tabela 3, o peso molecular do polibutadieno diminuiu com o aumento da razão molar DIBAH/Nd. Essa diminuição foi acompanhada pelo aumento da polidispersão, o que indica a ocorrência de reações de transferência de cadeia ${ }^{27,28}$.

Tabela 3. Influência da razão molar DIBAH/Nd sobre a conversão da polimerização de butadieno e sobre a polidispersão, o teor de unidades 1,4-cis e o peso molecular do polibutadieno ${ }^{28}$

\begin{tabular}{ccccc}
\hline $\begin{array}{c}\text { Razão molar } \\
\text { DIBAH/Nd }\end{array}$ & $\begin{array}{c}\text { Conversão } \\
(\%)\end{array}$ & $\begin{array}{c}\text { Teor 1,4-cis } \\
(\%)\end{array}$ & $\begin{array}{c}\overline{\mathrm{M}} \mathrm{w} \\
(\mathrm{g} / \mathrm{mol})\end{array}$ & $\overline{\mathrm{M} w / \overline{\mathrm{M}}}$ \\
\hline 10 & 64 & 99 & 390.000 & 3,0 \\
25 & 88 & 98 & 210.000 & 3,5 \\
30 & 90 & 98 & 180.000 & 4,1 \\
40 & 98 & 99 & 150.000 & 5,3 \\
60 & 98 & 96 & 110.000 & 7,8 \\
\hline
\end{tabular}

Mello $^{32}$ também estudou a influência da variação da razão molar $\mathrm{Al} / \mathrm{Nd}$ utilizando o DIBAH como cocatalisador, porém usou baixas concentrações desse alquilalumínio. A microestrutura do polibutadieno permaneceu inalterada na faixa estudada. O teor de unidades 1,4-cis ficou entre 97-98, 97-98 e 96-97 quando a razão Al/
$\mathrm{Nd}$ foi igual a 8,10 e 14, respectivamente. Como se pode verificar na Tabela 4, houve uma diminuição no peso molecular e um alargamento na polidispersão do polímero à medida que se aumentou a razão molar $\mathrm{Al} / \mathrm{Nd}$. Isso se deve ao fato de o alquilalumínio ser um agente de transferência de cadeia ativo, como mostrado na Equação 1. Nesse tipo de transferência, o sítio ativo fica disponível para iniciar uma nova cadeia polimérica.

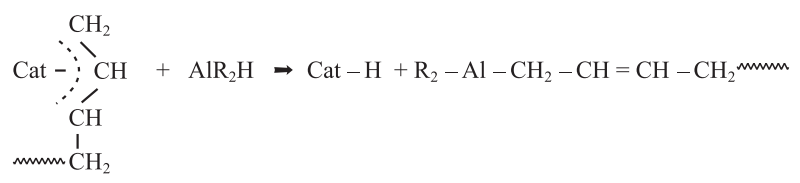

Tabela 4. Influência da razão molar Al/Nd sobre o peso molecular e a polidispersão ${ }^{32}$

\begin{tabular}{cccc}
\hline Razão molar Al/Nd & $\overline{\mathrm{M}} \mathrm{n}$ & $\overline{\mathrm{M}} \mathrm{w}$ & $\overline{\mathrm{M}} \mathrm{w} / \overline{\mathrm{M}} \mathrm{n}$ \\
\hline 8 & \multicolumn{4}{c}{ Gel, polímero não solubilizou * } \\
10 & 103000 & 411000 & 3,1 \\
14 & 44000 & 223000 & 5,0 \\
\hline
\end{tabular}

* Peso molecular muito alto

A dependência da microestrutura dos polidienos com o tipo de alquilalumínio utilizado também foi estudada por Monakov e colaboradores ${ }^{9}$. Variações na estrutura do alquilalumínio resultaram em variações no teor de unidades 1,4-cis e 1,4-trans no polibutadieno, enquanto que o teor total de ligações 1,2- permaneceu o mesmo para o TEA e o TIBA e aumentou quando DIBAH foi empregado (Tabela 5).

Tabela 5. Influência do tipo de alquilalumínio sobre a microestrutura do polibutadieno ${ }^{9}$

\begin{tabular}{cccc}
\hline AlR $_{3}$ & \multicolumn{3}{c}{ Teor de unidades $(\%)$} \\
\cline { 2 - 4 } & 1,4 -cis & 1,4-trans & 1,2-vinila \\
\hline TEA & 89,0 & 10,4 & 0,6 \\
DIBAH & 91,2 & 7,4 & 1,4 \\
TIBA & 94,5 & 5,0 & 0,5 \\
\hline
\end{tabular}

Quando a temperatura de polimerização foi aumentada, a dependência da estrutura do polibutadieno em relação ao alquilalumínio aumentou (Figura 12). Nesse caso, ocorreu uma diminuição no teor de ligações 1,4-cis, com o conseqüiente aumento do teor de ligações 1,4-trans ${ }^{9}$.

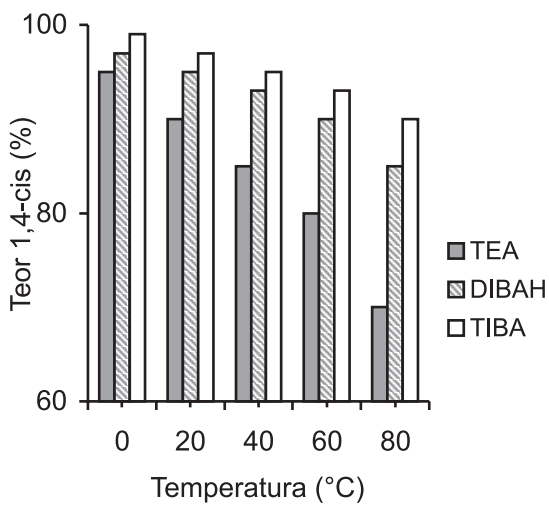

Figura 12. Variação do teor de ligações 1,4-cis no polibutadieno com a variação da temperatura de polimerização e da estrutura do alquilalumínio 
Coutinho e colaboradores ${ }^{33}$ estudaram a influência do tipo de alquilalumínio sobre a microestrutura do polibutadieno. Utilizando baixa pressão de butadieno e baixa temperatura, os autores verificaram que o teor de unidades 1,4-cis aumentava à medida que se diminuía o tamanho do substituinte ligado ao alumínio do cocatalisador.

\section{TEA $>$ DIBAH $>$ TIBA}

Esse resultado foi atribuído ao impedimento estérico causado pelo grupamento alquila, pois quando o substituinte ligado ao alumínio é menos volumoso, é permitida uma melhor orientação do 1,3-butadieno para a inserção 1,4-cis (Tabela 6). Resultados diferentes foram encontrados por outros autores ${ }^{8}$, provavelmente devido ao emprego de condições reacionais diferentes das utilizadas por Coutinho ${ }^{33}$

Tabela 6. Influência do tipo de alquilalumínio sobre a microestrutura do polibutadieno ${ }^{33}$

\begin{tabular}{cccc}
\hline AlR $_{3}$ & \multicolumn{3}{c}{ Teor de unidades (\%) } \\
\cline { 2 - 4 } & 1,4 -cis & 1,4-trans & 1,2-vinila \\
\hline TEA & 99,8 & 0,2 & 0,4 \\
DIBAH & 98,3 & 1,2 & 0,5 \\
TIBA & 97,6 & 2,0 & 0,4 \\
\hline
\end{tabular}

A variação da estrutura do radical alquila $(R)$ do alquilalumínio $\left(\mathrm{AlR}_{3}\right)$ tem um efeito pronunciado sobre a atividade do catalisador. A atividade de sistemas catalíticos pertencentes ao Grupo II segue a seguinte ordem em relação ao cocatalisador ${ }^{8,12,29}$ :

$\mathrm{Al}\left(\mathrm{i}-\mathrm{C}_{2} \mathrm{H}_{9}\right)_{2} \mathrm{H}>\mathrm{Al}\left(\mathrm{i}-\mathrm{C}_{4} \mathrm{H}_{9}\right)_{3}>\mathrm{Al}\left(\mathrm{C}_{2} \mathrm{H}_{5}\right)_{3}>\mathrm{Al}\left(\mathrm{CH}_{3}\right)_{3}$

A baixa atividade dos sistemas que incluem o trietilalumínio (TEA) está relacionada ao seu estado dimérico à temperatura ambiente.

Verifica-se na literatura ${ }^{8}$ que o aumento do comprimento do radical "R" do alquilalumínio provoca uma diminuição na sua capacidade de alquilação, o que causa uma queda na velocidade de polimerização, uma vez que há diminuição do número de centros ativos formados. No entanto, a reatividade permanece inalterada, pois a constante de velocidade de propagação e a estereoespecificidade não variam. $\mathrm{O}$ aumento do comprimento do radical alquila resulta em um aumento no peso molecular dos polidienos. De acordo com Marina e colaboradores ${ }^{8}$, isso ocorre devido à queda no valor da constante relativa de transferência de cadeia do $\mathrm{AlR}_{3}$.

A dependência da velocidade de polimerização e do número de centros ativos com a concentração de alquilalumínio é mostrada na Figura 13. No intervalo de razão molar estudado, o valor de $\mathrm{k}_{\mathrm{p}}$ permaneceu inalterado. A velocidade de polimerização aumentou quando a razão molar aumentou de 4 para 20. Em valores de razão $\mathrm{Al} / \mathrm{Nd}$ acima de 20, a velocidade de polimerização sofreu apenas uma ligeira variação (Figura 13$)^{8}$.

A constante relativa de transferência de cadeia para o alquilalumínio, em sistemas à base de lantanídeos, é menor que a constante de transferência no caso da polimerização de butadieno com sistemas à base de titânio, para o mesmo alquilalumínio. Isso assegura a produção de polibutadieno com mais alto peso molecular com catalisadores baseados em lantanídeos. Além disso, em baixas concentrações de $\mathrm{AlR}_{3}$, em presença desses catalisadores (Ln), a polimerização tem caráter de polimerização viva, e o peso molecular aumenta com a conversão ${ }^{8}$.

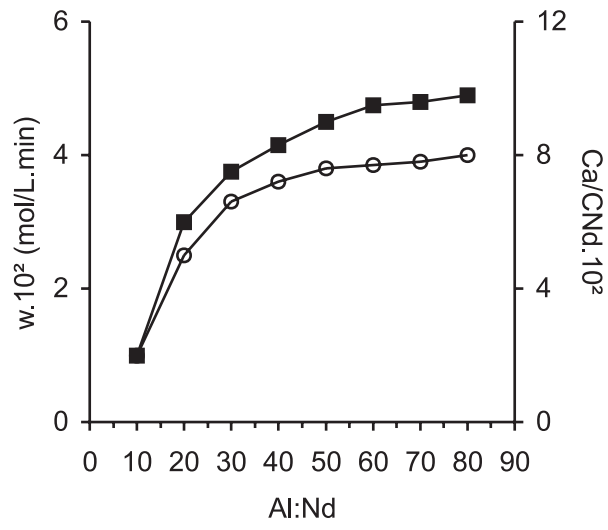

Figura 13. Variação da velocidade de polimerização (-口-) e do número de centros ativos (-O-) com a variação da razão molar Al/Nd na polimerização de butadieno com o sistema catalítico à base de neodímio

\section{Ordem de adição dos componentes do sistema catalítico}

A ordem de adição dos componentes do sistema catalítico afeta a conversão da polimerização, a polidispersão e o peso molecular dos polímeros obtidos.

Wilson ${ }^{18}$ estudou a influência da ordem de adição dos componentes do sistema catalítico sobre a distribuição de peso molecular do polibutadieno e observou que a ordem de adição $\mathrm{Al}+\mathrm{Nd}+\mathrm{Cl}$ produziu a mais estreita distribuição. $\mathrm{O}$ catalisador formado, quando se faz a adição dos componentes nessa ordem, é homogêneo e estável por semanas, enquanto que o sistema catalítico resultante da ordem de adição $\mathrm{Cl}+\mathrm{Nd}+\mathrm{Al}$ forma um precipitado após $20 \mathrm{~h}$, e a ordem de adição $\mathrm{Cl}+\mathrm{Al}+\mathrm{Nd}$ resulta em um catalisador que precipita quase que imediatamente, ou seja, a ordem de adição dos componentes afeta a heterogeneidade do sistema e, assim, a estabilidade do catalisador $^{34}$.

Quirk e colaboradore ${ }^{27}$ também estudaram a influência da ordem de adição dos componentes do sistema catalítico sobre as características da reação de polimerização e dos polímeros obtidos. $\mathrm{O}$ catalisador, preparado na ordem $\mathrm{Cl}+\mathrm{Nd}+\mathrm{Al}$ (heterogêneo), produziu menor conversão e mais larga polidispersão (Tabela 7).

Tabela 7. Influência da ordem de adição dos componentes do sistema catalítico sobre a conversão, a polidispersão, o peso molecular e o teor de unidades 1,4 - cis $^{27}$

\begin{tabular}{ccccc}
\hline $\begin{array}{c}\text { Ordem } \\
\text { de adição }\end{array}$ & $\begin{array}{c}\text { Conversão } \\
(\%)\end{array}$ & $\begin{array}{c}\overline{\mathrm{M}} \mathrm{w} \\
(\mathrm{g} / \mathrm{mol})\end{array}$ & $\overline{\mathrm{M}} \mathrm{w} / \overline{\mathrm{M}} \mathrm{n}$ & $\begin{array}{c}1,4-\text { cis } \\
(\%)\end{array}$ \\
\hline $\mathrm{Cl}+\mathrm{Nd}+\mathrm{Al}$ & 57 & 430.000 & 7,5 & 98 \\
$\mathrm{Al}+\mathrm{Cl}+\mathrm{Nd}$ & 76 & 390.000 & 5,7 & 97 \\
$\mathrm{Al}+\mathrm{Nd}+\mathrm{Cl}$ & 84 & 210.000 & 3,4 & 98 \\
\hline
\end{tabular}

Embora os catalisadores heterogêneos sejam inicialmente mais ativos, os catalisadores homogêneos (solúveis) fornecem altas conversões em menor intervalo de tempo (Figura 14). Pode-se supor que nos catalisadores heterogêneos existem dois tipos de sítios catalíticos. Assim sendo, a polimerização inicialmente procede de forma mais rápida, pois ocorre sobre a superfície das partículas insolúveis. Conforme as cadeias crescem, o acesso do monômero aos sítios (recobertos com polímero) torna-se mais difícil e, assim, as cadeias passam a crescer mais lentamente. O segundo tipo de crescimento de cadeia (homogêneo) ocorre de uma maneira quase viva ${ }^{34}$. 


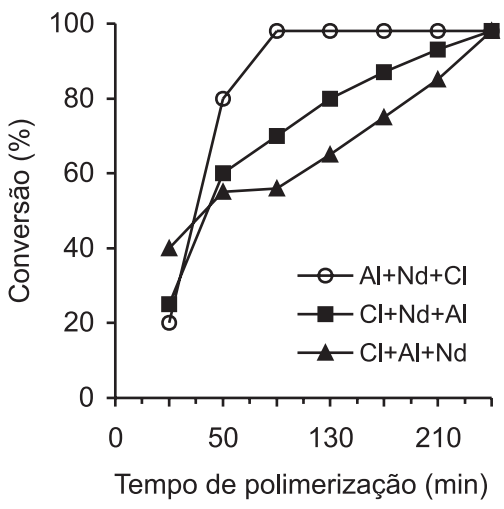

Figura 14. Influência da ordem de adição dos componentes catalíticos sobre a conversão da polimerização de butadieno

\section{Concentração de neodímio}

A variação do peso molecular em função da concentração de neodímio $[\mathrm{Nd}]$ é mostrada nas Figura 15. A diminuição tanto em $\overline{\mathrm{M}}$ como em $\overline{\mathrm{M}} \mathrm{w}$, com o aumento dessa concentração, pode ser atribuída, segundo Nickaf e colaboradores ${ }^{26}$, a um aumento no número de sítios ativos.

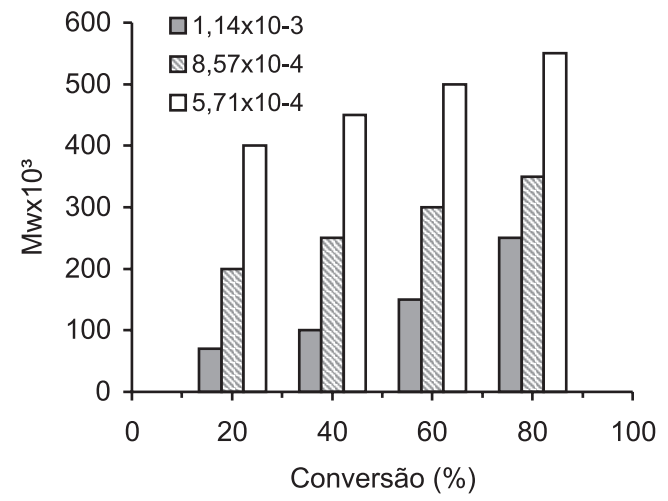

Figura 15. Influência da concentração de neodímio sobre o peso molecular do polibutadieno produzido

Oehme e colaboradores ${ }^{24}$ estudaram o efeito da concentração de neodímio sobre o peso molecular e o teor de unidades 1,4-cis do polímero obtido. Os autores verificaram que o peso molecular aumentava com o aumento da concentração de neodímio, já o teor de unidades 1,4-cis diminuía com o aumento dessa concentração (Figura 16).

Pires e colaboradores ${ }^{35}$ também estudaram o efeito da concentração de neodímio sobre a microestrutura do polibutadieno, porém utilizaram uma faixa de valores de concentração menor (Figura 17). Os autores concluíram que o teor de unidades 1,4-cis não era influenciado pela variação da concentração de neodímio, no intervalo estudado.

\section{Temperatura e tempo de envelhecimento do catalisador}

A temperatura e o tempo de envelhecimento do catalisador exercem influência sobre o peso molecular, a distribuição de peso molecular do polibutadieno e sobre a conversão da polimerização. A microestrutura é independente das condições de preparação do catalisador $^{36}$.

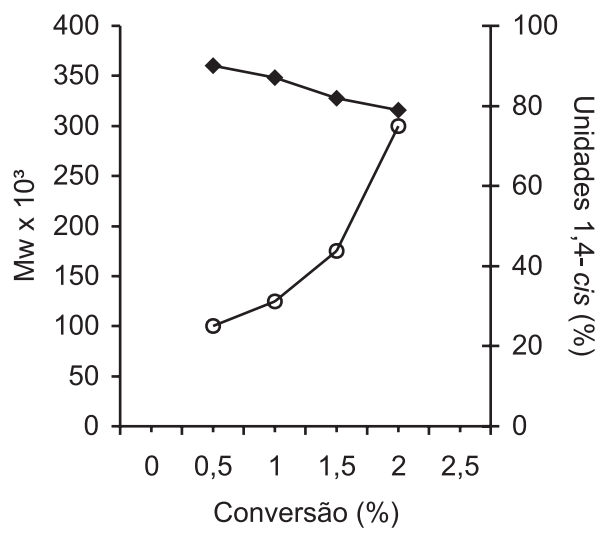

Figura 16. Variação do peso molecular (Mw) e do teor de unidades 1,4-cis em função da variação da concentração de neodímio: - - 1,4-cis; - $-\mathrm{Mw}$

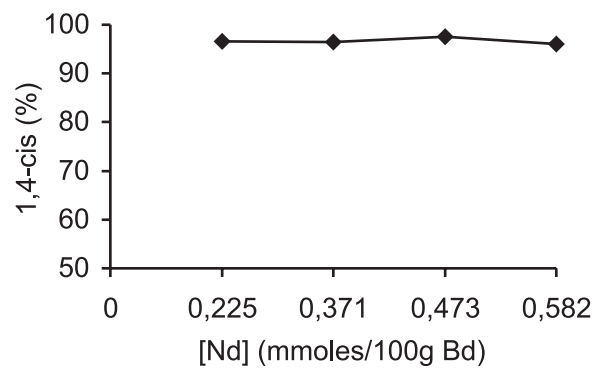

Figura 17. Influência da concentração de Nd sobre o teor de unidades 1,4-cis

Quando o catalisador é envelhecido a baixas temperaturas, a curva de SEC torna-se bimodal. Isso, provavelmente, ocorre devido à existência de dois tipos de centros ativos. O primeiro tipo corresponde ao pico na faixa de pesos moleculares mais baixos. Com o aumento da temperatura de envelhecimento do catalisador, esse pico deslocase para a região de pesos moleculares mais altos. Esses picos, provavelmente, coalescem a altas temperaturas $\left(80{ }^{\circ} \mathrm{C}\right)^{36}$.

A Figura 18 mostra que a conversão da polimerização diminui com o aumento do tempo de envelhecimento do catalisador devido à ocorrência de reações que levam a formação da ligação- $\sigma \mathrm{Nd}-\mathrm{C}$ (Equação 2).

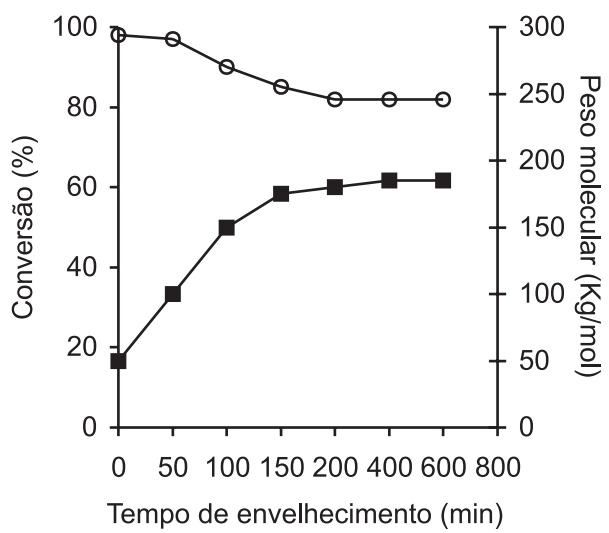

Figura 18. Efeito do tempo de envelhecimento do catalisador sobre a conversão da polimerização (-O-) e o peso molecular (-口-) do polibutadieno 1,4 -cis 


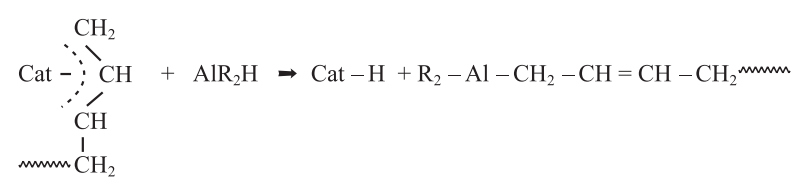

O peso molecular aumenta com o aumento do tempo de envelhecimento. Uma explicação para esse fato pode ser a relação entre os tipos de centros ativos, que durante tempos de envelhecimento longos é alterada. A concentração do primeiro tipo de centro ativo diminui com o aumento do tempo de envelhecimento. Sendo assim, o peso molecular pode aumentar com o aumento do tempo de envelhecimento.

A Figura 19 mostra a ocorrência de uma maior atividade do catalisador envelhecido a $25{ }^{\circ} \mathrm{C}$ do que a temperaturas mais baixas. Isso pode ser atribuído ao fato de a reação de alquilação ocorrer mais rapidamente a $25^{\circ} \mathrm{C}$. Pode-se notar que, em temperaturas superiores a $25^{\circ} \mathrm{C}$, há uma queda na conversão da polimerização devido à menor estabilidade da ligação- $\sigma \mathrm{Nd}-\mathrm{C}$ em temperaturas mais altas.

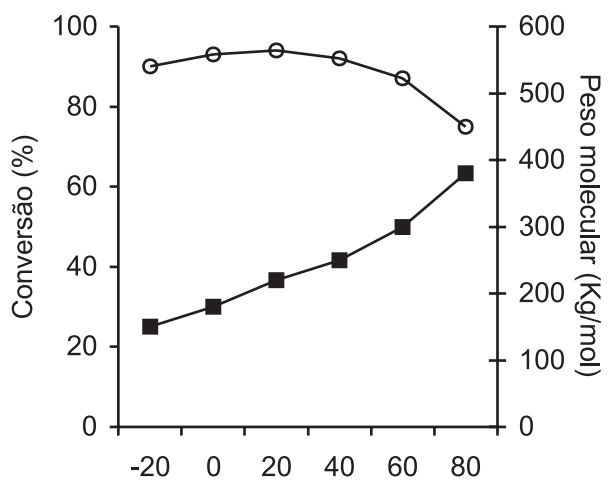

Temperatura de envelhecimento $\left({ }^{\circ} \mathrm{C}\right)$

Figura 19. Efeito da temperatura de envelhecimento do catalisador sobre a conversão da polimerização (-O-) e o peso molecular (-口-) do polibutadieno 1,4 -cis

\section{Natureza do solvente}

Entre os solventes que podem ser usados na polimerização de dienos com catalisadores à base de lantanídeos estão os alifáticos, cicloalifáticos, aromáticos e misturas desses hidrocarbonetos. Os resultados obtidos com esses diferentes solventes mostram que o rendimento da polimerização diminui na ordem solvente olefínico $\geq$ parafínico >> aromático ${ }^{8,37}$.

Compostos alifáticos, tais como ciclo-hexano ou heptano, são os solventes preferidos para a polimerização com catalisadores à base de neodímio ${ }^{38}$.

Os hidrocarbonetos aromáticos produzem menor rendimento de polímero e menor velocidade de polimerização do que os alifáticos. A diferença na atividade dos catalisadores é atribuída à influência do solvente sobre a constante de velocidade de propagação, que é três vezes maior na polimerização em heptano do que em tolueno. $\mathrm{O}$ tolueno entra na esfera de coordenação do lantanídeo (centro ativo) e, assim, diminui a sua capacidade de coordenação com o monômero e a estabilidade do complexo ${ }^{8,38}$.

O efeito da natureza do solvente sobre a velocidade de polimerização está representado na Figura 20. Em todos os casos, a velocidade de polimerização é maior em hidrocarbonetos alifáticos do que em aromáticos. A redução na constante de velocidade de propagação é atribuída à competição existente entre o hidrocarboneto aromático e o monômero pela coordenação com o centro ativo (Figura 21), uma vez que os compostos aromáticos podem se coordenar com o átomo de Nd do centro ativo. Isso faz com que a reação de polimerização ocorra mais lentamente pelo fato do hidrocarboneto aromático formar um complexo com o átomo de lantanídeo ${ }^{9,37,38}$.

A Figura 20 mostra claramente que a velocidade da reação diminui à medida que a densidade eletrônica do solvente aromático aumenta. Entre os solventes aromáticos, tolueno, benzeno e clorobenzeno, o tolueno é o que dá a velocidade mais baixa e o cloro benzeno, a mais alta.

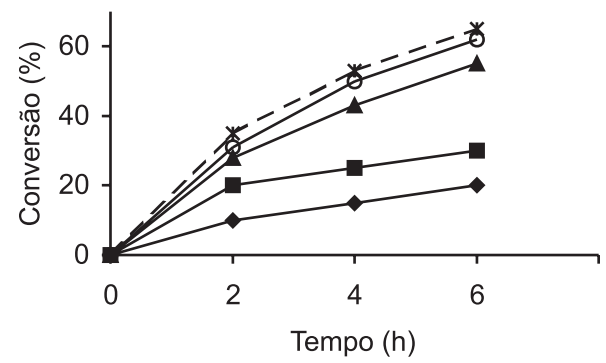

Figura 20. Curvas de conversão versus tempo para a polimerização de dienos. Polimerização conduzida em isopentano (-*-), n-heptano (-○-), clorobenzeno (- $\mathbf{\Delta - )}$, benzeno (-口-) e tolueno (- $\left.\boldsymbol{-}_{-}\right)$

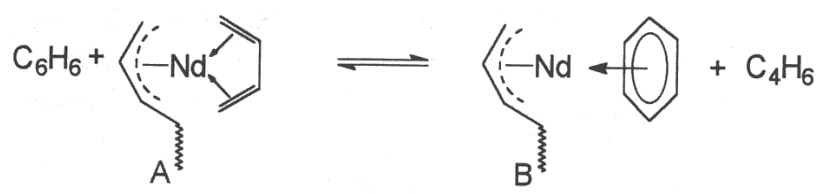

Figura 21. Representação esquemática da coordenação competitiva do monômero e do solvente aromático pelo átomo de $\mathrm{Nd}$ do centro catalítico

A espécie (A), onde o monômero está coordenado ao átomo de neodímio, é uma espécie ativa, que pode gerar uma nova unidade monomérica na cadeia, enquanto que a espécie (B) é inativa. Quanto maior a densidade eletrônica dos compostos aromáticos, mais deslocado para a direita é o equilíbrio dessa reação. Como consequiência, a concentração das espécies (A) diminui e, portanto, a velocidade de polimerização diminui com o aumento da basicidade do solvente aromático.

Não foi notada nenhuma influência da natureza do solvente sobre a estereoespecificidade do polibutadieno, em temperaturas próximas à temperatura ambiente. No entanto, sob altas temperaturas, a microestrutura dos polibutadienos produzidos em heptano e em tolueno são diferentes (Figura 22) ${ }^{9}$. Além disso, a polimerização em solventes alifáticos, quando comparada com a polimerização em solventes aromáticos, fornece polímeros com maior peso molecular ${ }^{8}$.

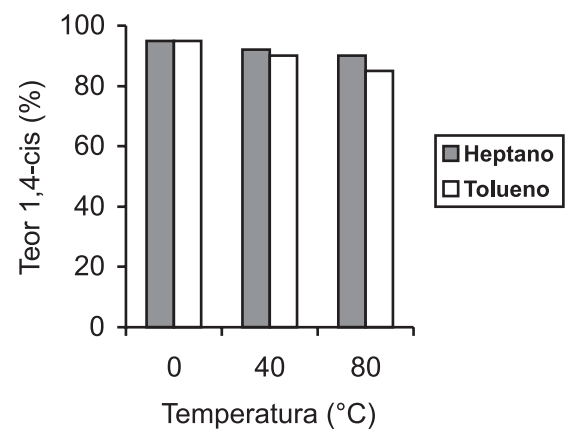

Figura 22. Teor de unidades 1,4-cis em polibutadieno como uma função da temperatura de polimerização. Polimerização conduzida em heptano e tolueno. Sistema catalítico, $\mathrm{NdCl}_{3} .3 \mathrm{TBP}-\mathrm{Al}\left(\mathrm{i}-\mathrm{C}_{4} \mathrm{H}_{9}\right)_{3}$ 
Na série de compostos aromáticos, a conversão diminui com o aumento do poder de doação de elétrons do solvente (Tabela 8) ${ }^{38}$.

Tabela 8. Polimerização de butadieno em diferentes solventes $\operatorname{aromáticos}^{38}$

\begin{tabular}{lc}
\hline Solvente & Conversão, \% \\
\hline Tolueno & 18 \\
Mesitileno & 11 \\
Tolueno $+7 \%$ hexametilbenzeno & Insignificante \\
\hline
\end{tabular}

Praticamente, nenhum polímero foi obtido quando se utilizou como solvente o tolueno contendo $7 \% \mathrm{p} / \mathrm{p}$ de hexametilbenzeno (HMB). Os autores concluíram que, provavelmente, o HMB por ser um composto com alta densidade eletrônica, se coordena tão fortemente com o catalisador que não pode ser deslocado pelo monômero.

Existem na literatura ${ }^{37,38}$ estudos sobre a utilização de alquenos como solventes de polimerização. A Figura 23 resume os resultados obtidos na utilização de alquenos, aromáticos e alcanos como solventes da polimerização de dienos. As maiores conversões foram obtidas com cis-buteno e cis-penteno. 1-Alquenos comportam-se de modo semelhante aos alcanos. Isobuteno e 2-metil-buteno também podem ser usados como solventes de polimerização, pois os catalisadores à base de Nd não são capazes de polimerizar esses alquenos por um mecanismo catiônico.

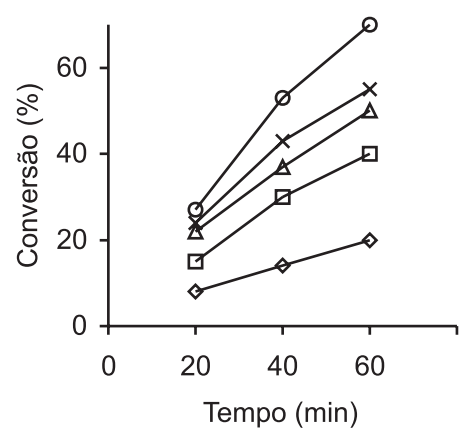

Figura 23. Curvas de conversão versus tempo. Polimerização de butadieno conduzida em tolueno $\left(-\diamond_{-}\right)$, heptano $(-\triangle-)$, heptano $+3 \%$ tolueno $(-\square-)$, 1-penteno (-X-) e cis-buteno (-O-)

Polidienos de mesmo peso molecular são obtidos tanto em heptano como em alquenos, o que significa que os alquenos não atuam como agentes de transferência de cadeia. Além disso, análises de NMR e espectroscopia na região do infravermelho dos polímeros obtidos em alquenos e em heptano são idênticas, o que indica que os alquenos usados como solventes não são incorporados à cadeia polimérica em crescimento $^{38}$.

Mello $^{32}$ estudou a influência da natureza do solvente sobre a microestrutura, o peso molecular e a distribuição de peso molecular do polibutadieno e o rendimento da reação utilizando dois solventes alifáticos, um de cadeia aberta (hexano) e o outro de cadeia fechada (ciclo-hexano) e misturas de ambos.

É de se esperar que a diferença nos resultados não seja acentuada ao se usar um ou outro solvente. Entretanto, como o ciclo-hexano apresenta um parâmetro de solubilidade $(\delta)$ maior que o hexano (Tabela 9) e próximo ao do polibutadieno, tem um poder maior de solvatação, isto é, proporciona uma maior solvatação do sítio ativo. Assim, a autora esperava que a variação do solvente da reação (ciclo-hexano, hexano e mistura de ambos) exercesse alguma influência sobre as características da reação e/ou do polibutadieno. Contu- do, os resultados obtidos não mostraram diferença na microestrutura (estereoespecificidade catalítica) quando esses sistemas foram usados como solventes das polimerizações de butadieno (Tabela 10).

Tabela 9. Parâmetros de solubilidade $(\delta)$ dos solventes e do polibutadieno $^{39}$

\begin{tabular}{lc}
\hline & $\delta\left(\mathrm{J} / \mathrm{cm}^{3}\right)^{1 / 2}$ \\
\hline Hexano & $14,8-14,9$ \\
Ciclo-hexano & 16,7 \\
Polibutadieno & 17,6 \\
\hline
\end{tabular}

Tabela 10. Influência da natureza do solvente sobre a microestrutura do polibutadieno ${ }^{32}$

\begin{tabular}{ccccc}
\hline \multirow{2}{*}{$\begin{array}{c}\text { Composição (\% v/v) } \\
\text { Hexano Ciclo-hexano }\end{array}$} & \multicolumn{3}{c}{ Microestrutura (\%) } \\
\hline 100 & 0 & 97,5 & 1,9 & 0,6 \\
80 & 20 & 97,6 & 1,8 & 0,6 \\
50 & 50 & 97,4 & 2,0 & 0,6 \\
20 & 80 & 97,0 & 2,5 & 0,6 \\
0 & 100 & 97,1 & 1,9 & 0,6 \\
\hline
\end{tabular}

Os dados da Tabela 11 mostram que tanto o peso molecular, como a distribuição de peso molecular não sofreram variação significativa com a variação do solvente da polimerização. Entretanto, nota-se uma tendência para pesos moleculares mais baixos nas polimerizações realizadas em meio rico em ciclo-hexano (melhor solvente para o polibutadieno). Isso pode ser atribuído ao fato de a reação de transferência de cadeia (controladora do peso molecular) ser mais favorecida em presença do melhor solvente $\mathrm{e}^{32,40,41}$.

Tabela 11. Influência da natureza do solvente sobre o peso molecular e distribuição de peso molecular do polibutadieno ${ }^{32}$

\begin{tabular}{ccccc}
\hline \multirow{2}{*}{ Composição (\% v/v) } & \multicolumn{2}{c}{ Peso molecular } & $\overline{\mathrm{M}} \mathrm{w} / \overline{\mathrm{M}} \mathrm{n}$ \\
Hexano Ciclo-hexano & $\overline{\mathrm{M}} \mathrm{n}$ & $\overline{\mathrm{M}} \mathrm{w}$ & \\
\hline 100 & 0 & $1,9 \times 10^{5}$ & $3,6 \times 10^{5}$ & 3,7 \\
80 & 20 & $1,0 \times 10^{5}$ & $4,1 \times 10^{5}$ & 3,5 \\
50 & 50 & $8,4 \times 10^{4}$ & $4,7 \times 10^{5}$ & 4,4 \\
20 & 80 & $5,7 \times 10^{4}$ & $2,9 \times 10^{5}$ & 5,0 \\
0 & 100 & $4,4 \times 10^{4}$ & $2,2 \times 10^{5}$ & 5,0 \\
\hline
\end{tabular}

Os resultados da Tabela 12 mostram que o sistema se apresentou bastante ativo para todas as composições de solvente, não se observando nenhum efeito sobre o rendimento da reação.

Tabela 12. Influência da natureza do solvente sobre o rendimento da reação ${ }^{32}$

\begin{tabular}{ccc}
\hline \multicolumn{2}{c}{ Composição } & Massa de polímero $(\mathrm{g})$ \\
Hexano & Ciclo-hexano & \\
\hline 100 & 0 & 30 \\
80 & 20 & 29 \\
50 & 50 & 30 \\
20 & 80 & 30 \\
0 & 100 & 29 \\
\hline
\end{tabular}




\section{Concentração de monômero}

Pires e colaboradores ${ }^{42}$ estudaram a influência da concentração de monômero sobre a microestrutura do polibutadieno e constataram uma ligeira influência pela variação da concentração do monômero, no intervalo de temperatura reacional estudado. Embora esse comportamento não seja acentuado, notou-se uma tendência de aumento do teor de unidades 1,4-cis à medida que a concentração de monômero diminuiu. Segundo os autores, esse comportamento pode ser atribuído à menor viscosidade do meio reacional que propicia uma maior mobilidade das moléculas de monômero, favorecendo assim a sua complexação na configuração adequada.

A Figura 24 mostra o perfil das curvas de tempo versus conversão em várias concentrações de butadieno, sob as mesmas condições reacionais. O perfil dessas curvas, em diferentes concentrações de butadieno, apresenta a mesma tendência, ou seja, a conversão aumenta com o aumento na concentração de monômero ${ }^{26}$.

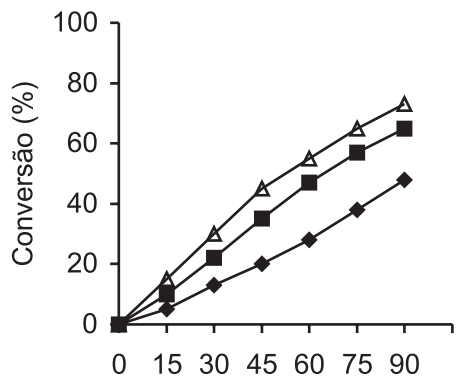

Tempo de polimerização (min)

Figura 24. Influência da concentração de butadieno sobre a conversão: - $[B d]=6,82 \% p / v,-\square-[B d]=10 \% p / v$ e $-\triangle-[B d]=14,43 \% p / v$

\section{AGRADECIMENTOS}

Ao Programa de Apoio às Entidades Estaduais (Proc. E-26/ 171.834/1999 e E-26/171.835/1999 FAPERJ), CNPq, Fundo de Apoio à Pesquisa no âmbito do Programa PROCIÊNCIA (FAP2000/ UERJ), FAPERJ (Bolsas Nota Dez de Mestrado e Cientista do Nosso Estado) e Petroflex Ind. e Com. S/A.

\section{REFERENCIAS}

1. Jenkins, D. K.; Ansell, P. J.; US pat. 5,017,539 1991.

2. Pires, N. M. T.; Coutinho, F. M. B.; Costa, M. A. S.; Santa Maria, L. C.; Mello, I. L.; Nunes, D. S. S.; Rev. Quím. Ind. 2002, 719, 15.

3. Jang, Y. C.; Kwag, G. H.; Kim, A. J.; Lee, S. H.; EP 1031583 A1 1999.

4. Nicolini, L. F.; Campos, C. R. A.; Lira, C. H.; Coutinho, P. L. A.; EP 1 055659 Al 2000.

5. Porri, L.; Ricci, G.; Shubin, N.; Macromol. Symp. 1998, 128, 53.

6. Ansell, P. J.; Williams, H. D.; US pat. 5,686,371 1997.

7. Steinhauser, N.; Obrecht, W.; US pat. appl. 200200352262002.
8. Marina, N. G.; Monakov, Y. B.; Rafikov, S. R.; Gadeleva, K. K.; Polym. Sci. U.S.S.R. 1984, 26, 1251.

9. Monakov, Y. B.; Marina, N. G.; Sabirov, Z. M.; J. Polym. Sci., Part A: Polym. Chem. 1994, 36, 1404.

10. Iovu, H.; Hubca, G. S. E.; Badea, E. H. J. S.; Eur. Polym. J. 1997, 33, 811.

11. Pross, A.; Marquardt, P.; Reichert, K. H.; Nentwig, W.; Knauf, T.; Angew Makromol. Chem. 1993, 211, 89.

12. 3rd Section, 4th Laboratory, Kirin Institute of Applied Chemistry, Academic Sinica; Sci. Sin. 1974, 17, 656

13. Shen, Z.; Inorg. Chim. Acta 1987, 140, 7.

14. Monakov, Y. B.; Sabirov, Z. M.; Marina, N. G.; J. Polym. Sci., Part A: Polym. Chem. 1996, 38, 232.

15. Yang, J.; Tsutsui, M.; Chen, Z.; Bergbreiter, D. E.; Macromolecules 1992, 15,230

16. Jenkins, D. K.; Wilson, D. J.; Polym. Bull. 1995, 34, 257.

17. Dolgoplosk, B. A.; Tinyakova, E. I.; Yakovlev, V. A.; Gol'shtein, S. B.; J. Polym. Sci., Part A: Polym. Chem. 1996, 38, 261.

18. Wilson, D. J.; Macromol. Symp. 1993, 66, 273.

19. Gehrke, K.; Boldt, D.; Gebauer, U.; Lechner, M. D.; Kautsch. Gummi Kunstst. 1996, 49, 510.

20. Gehrke, K.; Krüger, G.; Gebauer, U.; Lechner, M. D.; Kautsch. Gummi Kunstst. 1996, 49, 760.

21. Wilson, D. J.; Polymer 1993, 34, 3004

22. Fraga, L. A.; Tese de Mestrado, Universidade Federal do Rio de Janeiro, Brasil, 2002.

23. Porri, L.; Ricci, G.; Shubin, N.; Olefin Polymerization 2000, 749, 15

24. Oehme, A.; Gebauer, U.; Gehrke, K.; J. Mol. Catal. A: Chem. 1993, 82, 83.

25. Kozlov, V. G.; Sigaeva, N. N.; Nefedjev, K. V.; Savel'eva, I. G.; Marina, N. G.; Monakov, Y. B.; J. Polym. Sci., Part A: Polym. Chem. 1994, 32, 1237.

26. Nickaf, J. B.; Burford, R. P.; Chaplin, R. P.; J. Polym. Sci., Part A: Polym. Chem. 1995, 33, 1125.

27. Zhiquan, S.; Jun, O.; Fusong, W.; Zhenya, H.; Fusheng, Y.; Baogong, Q.; J. Polym. Sci., Part A: Polym. Chem. 1980, 18, 3345.

28. Quirk, R. P.; Kells, A. M.; Yunlu, K.; Cuif, J. P.; Polymer 2000, 41, 5903.

29. Porri, L.; Giarrusso, A.; Shubin, N.; Lu, Z.; Ricci, G.; Polym. Prepr. (Am. Chem. Soc., Div. Polym. Chem.) 1998, 39, 214.

30. Wilson, D. J.; J. Polym. Sci., Part A: Polym Chem. 1995, 33, 2505.

31. Oehme, A.; Gebauer, U.; Gehrke, K.; Beyer, P.; Hartman, B.; Lechner, M. D.; Macromol. Chem. Phys. 1994, 195, 3773.

32. Mello, I. L.; Tese de Mestrado, Universidade Federal do Rio de Janeiro, Brasil, 2003.

33. Fraga, L. A.; Coutinho, F. M. B.; Costa, M. A. S.; Tavares, M. I. B.; Polímeros: Ciência e Tecnologia, submetido.

34. Wilson, D. J.; Jenkins, D. K.; Polym. Bull. 1992, 27, 407.

35. Pires, N. M. T.; Coutinho, F. M. B.; Costa, M. A. S.; Anais do $5^{\circ}$ Congresso Brasileiro de Polímeros, Gramado, Brasil, 2000.

36. Oehme, A.; Gebauer, U.; Gehrke, K.; Die Angew Makromol. Chem. 1996, $235,121$.

37. Ricci, G.; Boffa, G.; Porri, L.; Macromol. Rapid Commun. 1986, 7, 355.

38. Cabassi, F.; Italia, S.; Ricci, G.; Porri, L. Em Transition metal catalyzed polymerizations Ziegler-Natta and metathesis polymerizations; Quirk R. P., ed.; Cambridge University Press: Cambridge, 1988.

39. Krevelen, V. D. W.; Properties of polymers, Elsevier: Amsterdam, 1990.

40. Nunes, D. S. S.; Mello, I. L.; Coutinho, F. M. B.; Costa, M. A. S.; Maria, L. C. S.; CDRom do XV Congresso Brasileiro de Engenharia e Ciências de Materiais, Natal, Brasil, 2002.

41. Mello, I. L.; Coutinho, F. M. B.; Nunes, D. S. S.; Soares, B. G.; Ferreira, A. A.; Costa, M. A. S.; Maria, L. C. S.; Polym. Bull., submetido.

42. Pires, N. M. T.; Coutinho, F. M. B.; Costa, M. A. S.; Anais do $6^{\circ}$ Congresso Brasileiro de Polímeros/IX International Macromolecular Colloquim, Gramado, Brasil, 2001. 